\title{
Depression, Anxiety and Stress among nursing officers in a dedicated hospital for COVID patients in Sri Lanka: A Single Institute Experience
}

\author{
Pathirajage Deepthi Madushan Pathiraja', Wallagoda Samantha Srikanthi², \\ Bernard Deepal Wanniarachchi Jayamanne ${ }^{3}$, Hewage Sanduni DeSilva
}

\begin{abstract}
The main objective of this study was to assess the prevalence of stress, anxiety and depression, among nurses working in a tertiary hospital dedicated to the COVID-19 patients in Sri Lanka. A cross-sectional study was carried out among nurses working at Colombo East Base Hospital. The data was collected using a self-administered questionnaire and DASS-21, a set of three self-report scales designed to measure the negative emotional states of depression, anxiety, and stress over three months from October 2020. Data were analysed applying descriptive statistics and inferential statistical methods. There was a total of 131 study participants (response rate $83 \%$ ), and most of them were working in general wards (56\%), while $42 \%$ were in critical care units. The proportion of anxiety and stress is associated with nurses working in critical care units were significantly higher than those in general wards $(p<0.001)$. There were no associations between sex, marital status, having children, experience, qualifications, and medical or psychiatric conditions $(p>0.05)$. The system of reporting mental health issues was unfortunately not in place. Staff felt that reporting stress/burnout or anxiety might seem like a negative attribute. Considering the above factors, one would expect more prevalence than we have seen in this study; therefore, we can infer that if mental health is not prioritised in healthcare institutions, then definitely lack of awareness/openness and under-reporting by staff will result in a long-term systemic problem (Suffering in the name of Resilience).
\end{abstract}

KEYWORDS: Depression, Anxiety, Stress, Nursing Staff, COVID-19 pandemic, DASS 21.

doi: https://doi.org/10.12669/pjms.38.4.5508

How to cite this:

Pathiraja PDM, Srikanthi WS, Jayamanne BDW, DeSilva HS. Depression, Anxiety and Stress among nursing officers in a dedicated hospital for COVID patients in Sri Lanka: A Single Institute Experience. Pak J Med Sci. 2022;38(4):1073-1076. doi: https://doi.org/10.12669/pjms.38.4.5508

This is an Open Access article distributed under the terms of the Creative Commons Attribution License (http://creativecommons.org/licenses/by/3.0), which permits unrestricted use, distribution, and reproduction in any medium, provided the original work is properly cited.

1. Pathirajage Deepthi Madushan Pathiraja, MBBS, MD, MSLCOG, MRCOG. Consultant Obstetrician and Gynaecologist, The Ministry of Health, Sri Lanka.

2. Wallagoda Samantha Srikanthi, BSc-Nursing, Nursing Officer, Department of Obstetrics, Colombo East Base Hospital, Sri Lanka.

3. Bernard Deepal Wanniarachchi Jayamanne, MBBS, MSc (Biostatistics), MSc (Biomedical), MIASSL, Faculty of Medicine, University of Kelaniya, Sri Lanka.

4. Hewage Sanduni DeSilva, MBBS.

Senior Medical Officer, Department of Obstetrics, Colombo East Base Hospital, Sri Lanka.

Correspondence:

Pathirajage Deepthi Madushan Pathiraja, Department of Obstetrics, The Ministry of Health, Sri Lanka.

E-mail: madushan_pathi@yahoo.com

* Received for Publication:

October 10, 2021

* Revision Received:

January 21, 2022

* Revision Accepted:

January 28,2022

\section{INTRODUCTION}

Global pandemics have occurred in regular intervals in the past few decades. The health system has faced immense changes during SARS (severe acute respiratory syndrome), MERS (Middle East Respiratory Syndrome), and the H1N1 pandemic. World Health Organization (WHO) declared the COVID-19 a global pandemic in March 2020. ${ }^{1}$

Studies have shown that pandemics exacerbate the stress and anxiety levels among health care staff as they cope with intense physical, emotional, and cognitive demands., ${ }^{2,3}$ The psychological wellbeing of health care members is conditioned by the resources available at the settings and dedication by the governing bodies. To ensure safe, consistent 
practice, accurate data on current experiences are vital. Especially, those who work as frontline workers are subject to additional stress as they directly engage with infected patients. ${ }^{4,5}$ On the other hand, there was a fear of disease being transmitted to their family members, concerns about their children health and safety, fear of being stigmatised and rejected in the community, especially in different cultural backgrounds.

\section{METHODS}

This survey was conducted in Colombo East Base Hospital (CEBH), Colombo, Sri Lanka. All frontline nurses who were directly involved with the care of COVID-19 positive patients were invited to the study. Nurses who already had COVID-19 infection and/ or pregnant women were excluded.

A self-administered questionnaire was developed to recruit the socio-demographic, personal health, and work-related characteristics. Further, Depression Anxiety and Stress Scale (DASS) scale were used to assess the psychological wellbeing of the study participants. The DASS is a 21-item selfreport instrument developed initially by Lovibond et al. (1995) to measure the three negative emotional states of depression, anxiety, and stress level. ${ }^{6}$

It has been validated to Sinhala and Tamil versions and is freely available. ${ }^{7}$ Each sub-scale consists of seven items and is rated using a fourpoint scale, ranging from zero to three. (e.g., $0="$ did not apply to me at all" and three "applied to me very much or most of the time"). The total score was calculated by summing up the scores on each item on the sub-scale. This questionnaire is a public domain and requires no permission for use. ${ }^{8}$

An informed written consent was obtained from the participants. The researcher collected data over a period of three months from October 2020 onwards. Data were coded, entered on a spreadsheet (Microsoft Excel), and analysed by employing descriptive and inferential statistical methods using SPSS software (version 22). The study was conducted under the ethical standards and criteria and approved by the ethics committee at National Institute for Mental Health (NIMH), Colombo. Ref: (168/12/2020)

\section{RESULTS}

All frontline nurses who were directly involved with the care of COVID-19 positive patients were invited to the study, and a total of 131 respondents (response rate $83 \%$ ) were recruited. Most nurses were working in general wards $(56.5 \%)$, while
$42 \%, 2.3 \%$ worked in the critical care units and administrative departments, respectively. The majority were females (85.6\%), and the mean age was 35.5 years $( \pm 8.6) .76 \%$ of study participants were married, and $80 \%$ lived with their families. Further, $80 \%$ of married respondents had children. Nearly $70 \%(n=92)$ had less than five years of experience, and $26(n=34)$ had bachelor's degrees in addition to the basic diploma. We noted that $15 \%$ had medical comorbidities (diabetes, hypertension, asthma), and $2 \%$ had psychiatric issues such as mild personality and eating disorders and were on regular medications.

Results revealed that $29.9 \%$ were depressed, $29.8 \%$ were suffering from anxiety, and $19.8 \%$ were stressed at various levels (Table-I). The proportion of depressed, with anxiety and stressed with other socio-demographic factors are listed in Table-II.

The mean age of nurses with anxiety group (33.4 years) was found to be significantly lower than those without anxiety (36.4 years) ( $\mathrm{p}$-value $=$ 0.046). Further, a significant association between the unit that they are working with their anxiety $(p$-value $=0.03)$ and depression levels ( $p$-value $=<$ $0.001)$. There are no associations with sex, marital status, having children, experience, qualifications, medical or psychiatric issues ( $p$-value $>0.05$ ) (Table-III). There was a significant strong positive correlation among the three domains. The Spearman correlation coefficient was 0.84 $(\mathrm{p}<0.001), 0.85(\mathrm{p}<0.001)$ and $0.87(\mathrm{p}<0.001)$ respectively.

\section{DISCUSSION}

Sri Lanka's healthcare system is governed primarily by the public sector. ${ }^{9}$ During the pandemic, an overwhelming impact on the mental aspect of health care workers became evident, which would impose a considerable effect on their mental wellbeing. ${ }^{10,11}$ It was apparent that significant association of depression and anxiety scores with the unit that they are working

Table-I: Levels of depression, anxiety and stress among the study group.

\begin{tabular}{lccc}
\hline & Depression (\%) & Anxiety (\%) & Stress (\%) \\
\hline Normal & $103(78.6)$ & $92(70.2)$ & $105(80.2)$ \\
Mild & $13(9.9)$ & $08(6.1)$ & $13(9.9)$ \\
Moderate & $10(7.6)$ & $14(10.7)$ & $07(5.3)$ \\
Severe & $03(2.3)$ & $12(9.2)$ & $05(3.8)$ \\
Extremely & $02(1.5)$ & $05(3.8)$ & $01(0.8)$ \\
Severe & & & \\
\hline
\end{tabular}


Table-II: Proportion of depressed, with anxiety and stressed with socio-demographic factors of the sample.

\begin{tabular}{|c|c|c|c|c|c|c|c|}
\hline \multirow[t]{2}{*}{ Factor } & & \multicolumn{2}{|c|}{ Depression } & \multicolumn{2}{|c|}{ Anxiety } & \multicolumn{2}{|c|}{ Stress } \\
\hline & & Yes & No & Yes & No & Yes & No \\
\hline \multirow[t]{2}{*}{ Sex } & Male & $04(26.7 \%)$ & $11(73.3 \%)$ & $83(71.6 \%)$ & $09(60.0 \%)$ & $05(33.3 \%)$ & $10(66.7 \%)$ \\
\hline & Female & $24(20.7 \%)$ & $92(79.3 \%)$ & $33(28.4 \%)$ & $83(71.6 \%)$ & $21(18.1 \%)$ & 95 (81.9\%) \\
\hline \multirow[t]{2}{*}{ Marital status } & Married & $21(21.0 \%)$ & 79 (79.0\%) & $33(33.0 \%)$ & $67(67.0 \%)$ & $20(20.0 \%)$ & $80(80.0 \%)$ \\
\hline & Other & $07(22.6 \%)$ & $24(77.4 \%)$ & 06 (19.4\%) & $25(80.6 \%)$ & 06 (19.4\%) & $25(80.6 \%)$ \\
\hline \multirow[t]{2}{*}{ Have Children } & Yes & $20(25.0 \%)$ & $60(75.0 \%)$ & $26(32.5 \%)$ & $54(67.5 \%)$ & $17(21.2 \%)$ & $63(78.8 \%)$ \\
\hline & No & 08 (15.7\%) & $43(84.3 \%)$ & $13(25.5 \%)$ & $38(74.5 \%)$ & $42(82.4 \%)$ & 09 (17.6\%) \\
\hline \multirow{2}{*}{$\begin{array}{l}\text { Living with } \\
\text { family }\end{array}$} & Yes & $23(21.9 \%)$ & 05 (19.2\%) & $31(29.5 \%)$ & $74(70.5 \%)$ & $20(19.0 \%)$ & $85(81.0 \%)$ \\
\hline & No & $82(78.1 \%)$ & $21(80.8 \%)$ & 08 (30.8\%) & $18(69.2 \%)$ & $06(23.1 \%)$ & $20(76.9 \%)$ \\
\hline \multirow[t]{3}{*}{ Experience } & $<1$ year & $05(38.5 \%)$ & 08 (61.5\%) & $05(38.5 \%)$ & $08(61.5 \%)$ & $05(38.5 \%)$ & 08 (61.5\%) \\
\hline & 1- 5 years & $07(26.9 \%)$ & 19 (73.1\%) & $10(38.5 \%)$ & $16(61.5 \%)$ & $07(26.9 \%)$ & 19 (73.1\%) \\
\hline & $>5$ years & $16(17.4 \%)$ & $76(82.6 \%)$ & $24(26.1 \%)$ & $68(73.9 \%)$ & $14(15.2 \%)$ & 78 (84.8\%) \\
\hline \multirow[t]{2}{*}{ Qualifications } & Diploma & $18(18.6 \%)$ & 79 (81.4\%) & $26(26.8 \%)$ & $71(73.2 \%)$ & $15(15.5 \%)$ & $82(84.5 \%)$ \\
\hline & Bachelor & $10(29.4 \%)$ & $24(70.6 \%)$ & $13(38.2 \%)$ & $21(61.8 \%)$ & $11(32.4 \%)$ & $23(67.6 \%)$ \\
\hline \multirow[t]{3}{*}{ Working unit } & General & $12(16.2 \%)$ & $62(83.8 \%)$ & $16(21.6 \%)$ & $58(78.4 \%)$ & 07 (09.5\%) & 67 (90.5\%) \\
\hline & Critical & $16(29.6 \%)$ & 38 (70.4\%) & $22(40.7 \%)$ & $32(59.3 \%)$ & $19(35.2 \%)$ & $35(64.8 \%)$ \\
\hline & Admin & $0(0.0 \%)$ & $03(100.0 \%)$ & $01(33.3 \%)$ & $02(66.7 \%)$ & $0(00.0 \%)$ & $03(100.0 \%)$ \\
\hline \multirow[t]{2}{*}{ Medical issues } & Yes & $08(40.0 \%)$ & $12(60.0 \%)$ & $08(40.0 \%)$ & $12(60.0 \%)$ & $05(25.0 \%)$ & 15 (75.0\%) \\
\hline & No & $20(18.0 \%)$ & $91(82.0 \%)$ & $31(27.9 \%)$ & $80(72.1 \%)$ & $21(18.9 \%)$ & $90(81.1 \%)$ \\
\hline \multirow{2}{*}{$\begin{array}{l}\text { Psychiatric } \\
\text { illnesses }\end{array}$} & Yes & $01(33.3 \%)$ & 02 (66.7\%) & $01(33.3 \%)$ & $02(66.7 \%)$ & $01(33.3 \%)$ & $02(66.7 \%)$ \\
\hline & No & $27(21.1 \%)$ & $101(78.9 \%)$ & $38(29.7 \%)$ & $90(70.3 \%)$ & $25(19.5 \%)$ & $103(80.5 \%)$ \\
\hline
\end{tabular}

$(\mathrm{p}=0.004)$. Working conditions of the different units, especially the direct contact with infected patients, may have contributed to these findings. In addition, the workload, support available and restrictions to personal lifestyle at various levels may have been different. Similar results were reported in studies conducted in other south Asian countries. ${ }^{12,13}$

Considering the unprecedented manner and high risk involved with the pandemic, some degree of stress, anxiety, and even insomnia must be anticipated. However, further clinical assessment is warranted to confirm the presence of depressive disorder in those with high scores. Furthermore, detailed assessments of contributory psychological factors are needed. Comparatively, high reported anxiety and stress levels were observed in nurses who worked in critical care units. A system of reporting mental health issues is unfortunately not in place. ${ }^{14}$ The staff reported stress, burnout, or anxiety at the workplace as a negative attribute or weakness. Further, Stigmatisation regarding psychological issues, lack of awareness about these impacts on quality of life and patient care. The lack of understanding about concepts like burnout may have contributed to the

Table-III: Association of factors with depression, anxiety and stress status by Chi square test.

\begin{tabular}{|c|c|c|c|c|c|c|c|}
\hline \multirow{2}{*}{ Factor } & \multirow[t]{2}{*}{$d f$} & \multicolumn{2}{|c|}{ Depression } & \multicolumn{2}{|c|}{ Anxiety } & \multicolumn{2}{|c|}{ Stress } \\
\hline & & Test statistic & p value & Test statistic & pvalue & Test statistic & $p$ value \\
\hline Sex (Male/Female) & 1 & 0.038 & 0.84 & 0.385 & 0.53 & 1.098 & 0.29 \\
\hline Marital status (Married/Other) & 1 & 0.000 & 0.99 & 1.505 & 0.22 & 0.000 & 0.99 \\
\hline Have children (Yes/No) & 1 & 1.101 & 0.29 & 0.435 & 0.51 & 0.078 & 0.78 \\
\hline Living with family (Yes/No) & 1 & 0.000 & 0.97 & 0.000 & 0.99 & 0.035 & 0.85 \\
\hline Experience $(<1 \mathrm{y}, 1-5 \mathrm{y},>5 \mathrm{y})$ & 2 & 3.603 & 0.16 & 2.006 & 0.37 & 4.889 & 0.09 \\
\hline Qualifications (Diploma/Bachelor) & 1 & 1.178 & 0.28 & 1.074 & 0.30 & 3.515 & 0.06 \\
\hline Unit (Critical / Other ) & 1 & 2.549 & 0.11 & 4.589 & $0.03^{*}$ & 11.220 & $<0.01^{*}$ \\
\hline Medical issues (Yes/No) & 1 & 3.652 & 0.06 & 0.674 & 0.41 & 0.104 & 0.75 \\
\hline Psychiatric diseases $^{\S}(\mathrm{Yes} / \mathrm{No})$ & 1 & 0.520 & 0.52 & 0.000 & 0.99 & 0.351 & 0.49 \\
\hline
\end{tabular}

*Significant associations; § - Fisher exact test. 
aforementioned findings. A cross-sectional survey among health care workers in Pakistan showed how much they performed their duties diligently during the outbreak; however, they were much concerned and were afraid of infecting their family members. ${ }^{12}$ The authors highlight the importance of continued moral and financial support by the government and other health care organizations to appreciate their services.

Further, it was observed that the nurses belonging to the younger age group experienced a higher degree of anxiety. Less resilience to workplace stressors and limited experience may have contributed to this difference. Similar results were demonstrated by a study among nurses in a tertiary care hospital of India where anxiety and depression levels were more in the younger and less experienced nurses. ${ }^{13}$ A systematic review by Sonja et al. revealed an increased risk of stress-related disorders, fear of the unknown or becoming infected were at the forefront of the mental challenges faced. Being a nurse and being female appeared to confer more significant risk. ${ }^{15}$

This study highlights the importance of psychological awareness and support for the health care workers facing the current pandemic. Considering the issues of underreporting, stigma, and lack of awareness, it is justified to expect a higher prevalence of psychological problems than the findings of this study. Therefore, interventions to address these gaps in services need to be established to improve the psychological wellbeing of the health care workers. These will enhance the quality of life of the service providers and improve the quality of patient care and health services. Change needs to start at the level of policymakers to offer an enhanced variety of supports to nurses and other health care workers who play a critical role during large-scale disease outbreaks.

Acknowledgements: We would like to thank Dr. Priyantha Karunarathna, the director of CEBH; all the nursing staff who had given their valuable comments and care of the patients. Our sincere thanks to Ms. HKS Sunethra, Dr. Junaid Rafi, and Dr. Iresh Perera helped edit the article's final version.

Conflict of Interest: No conflict of interest has been declared by the authors.

\section{Grant Support \& Financial Disclosures: None.}

Data availability statement: The data that support the findings of this study are available from the corresponding author upon reasonable request.

\section{REFERENCES}

1. World Health Organization. Coronavirus disease 2019 situation report - 81. Geneva, Switzerland: World Health Organization; 2020. https://www.who.int/docs/default-source/ coronaviruse/ situation-reports/20200410-sitrep-81-covid-19. pdf?sfvrsn=ca96eb84_2

2. Silwal M, Koirala D, Koirala S, Lamichhane A. Depression, Anxiety and Stress among Nurses during COVID-19 Lockdown in a Hospital of Kaski District, Nepal. J Health Allied Sci. 2020;10(2):82-87. doi: 10.37107/jhas.210

3. Fernandez PR, Lord H, Halcomb PE, Moxham PL, Middleton DR, Alananzeh DI, et al. Implications for COVID- 19: A systematic review of nurses' experiences of working in acute care hospital settings during a respiratory pandemic. Int J Nursing Stud. 2020;111:103637. doi: 10.1016/j.ijnurstu.2020.103637

4. Karki P, Katwal GBJ, Chandra A, Chandra A. Prevalence and measurement of Anxiety and Depression in Nurses during Covid Pandemic in Nepal. Res Square. 2020; doi: 10.21203/ rs.3.rs-34462/v1

5. Lai J, Ma S, Wang Y, Cai Z, Hu J, Wei N, et al. Factors associated with mental health outcomes among health care workers exposed to coronavirus disease 2019. JAMA Netw Open. 2020;3(3):e203976. doi: 10.1001/jamanetworkopen. 2020.3976

6. Lovibond SH, Lovibond PF. (1995). Manual for the Depression Anxiety Stress Scales (2nd Ed.). Sydney: Psychology Foundation.

7. Suraweera C, Hanwella T. Rating Scales validated for Sri Lankan populations. Sri Lanka J Popul Stud. 2013;4(2):16-24. doi: 10.4038/sljpsyc.v4i2.6314

8. Wardenaar KJ, Wanders RBK, Jeronimus BF, Jonge P. The Psychometric Properties of an Internet- Administered Version of the Depression Anxiety and Stress Scales (DASS) in a Sample of Dutch Adults. J Psychopathol Behav Assessment. 2018;40:318333. doi: 10.1007/s10862- 017-9626-6

9. Fernando D. Health care system in transition 111, Sri Lanka. Part I. An overview of Sri Lanka's health care system J Public Health Med. 2000;22(1):14-20. doi: 10.1093/pubmed/22.1.14

10. Saqlain M, Munir MM, Ali A, Tahir AH, Kamran S. Is Pakistan prepared to tackle the coronavirus epidemic? Drugs Ther Perspect. 2020;36:213-214. doi: 10.1007/s40267-020-00721-1

11. Ghosh A, Nundy S, Mallick TK. How India is dealing with COVID-19 pandemic. Sensors Int. 2020; doi: 10.1016/j.sintl.2020.100021

12. Noreen K, Umar M, Sabir SA, Rehman R. Outbreak of Coronavirus Disease 2019 in Pakistan: Psychological impact and coping strategies of Health Care Professionals. Pak J Med Sci. 2020;36(7):1478-1483. doi: 10.12669/pjms.36.7.2988

13. Shajan A, Nisha C. Anxiety and Depression among nurses working in a tertiary care hospital in South India. Int J Adv Med. 2019;6(5):1611-1615. doi: 10.18203/2349-3933.ijam20194228

14. Latif F, Ahmed SR, Farhan S, Watt F, Azeem MW. Predictors of Psychological Distress in Health Care Staff in Qatar during COVID-19 Pandemic. Pak J Med Sci. 2021;37(7):1782-1787. doi: 10.12669/pjms.37.7.4533

15. Sonja C, Nadjidai Sarah E. Jerome M, Ng Chee H. The psychological impact of COVID-19 and other viral epidemics on frontline healthcare workers and ways to address it: A rapid systematic review. Brain Behav Immun Health. 2020;8:100144. doi: 10.1016/j.bbih.2020.100144

\section{Authors' Contribution:}

PDM: Conceived, designed, writing \& editing of manuscript, and final approval.WAS: Conceived, Data collection and final approval of manuscript. BDJ: Data analysis and final approval. SDS: Data collection, writing of manuscript and final approval of manuscript. 